\title{
دراسة الاستقرار الاقتصادى للصادرات المصرية من البطاطس إلى دول الإتحاد الأوربى
}

\author{
أمينة أمين قطب مصطفى \\ قسم الإقتصاد الزراعى - كلية الزراعة- جامعة الزقازيق
}

(الملخص:

استهدف هذا البحث تقدير الإتجاه الزمنى العام لكل من المساحة والإنتاج وتكاليف الإنتاج لمحصول البطاطس فى مصر خلال الفترة 1999-

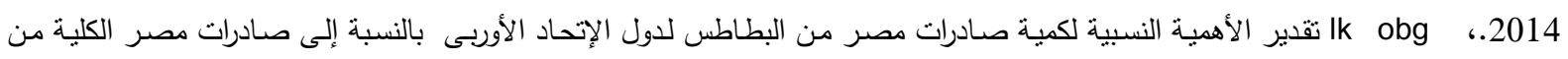

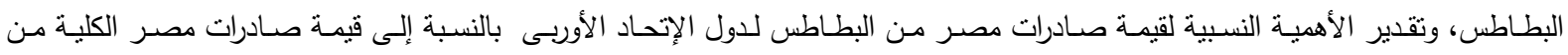

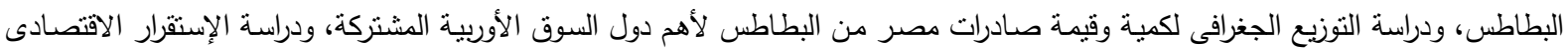

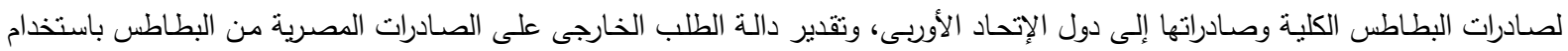
نموذج المشاركة السوقية. وتم الإعتماد على البيانات الثانوية المنشورة وغير المنشورة، والصادرة من كل من الجهاز المركزي للتعبئة العامة والإحصاء ووزارة الزراعة،

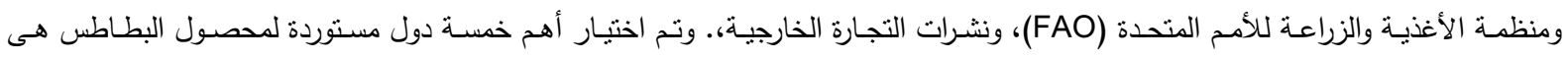

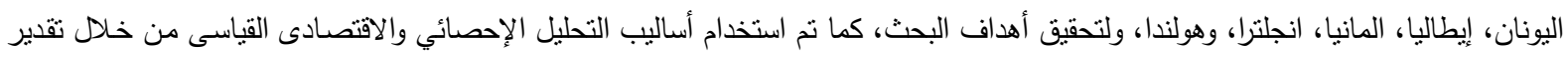

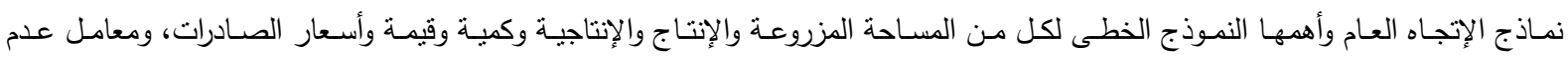

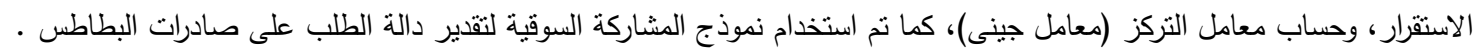

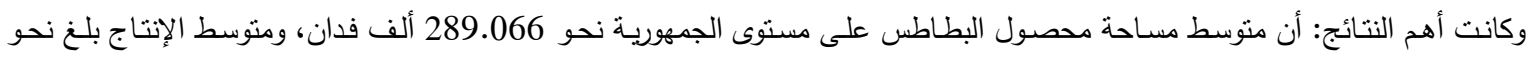

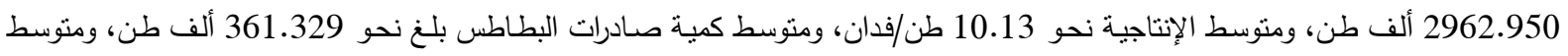

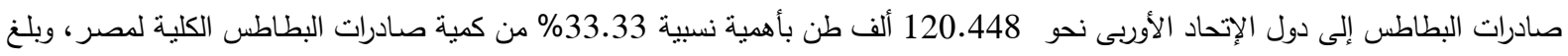

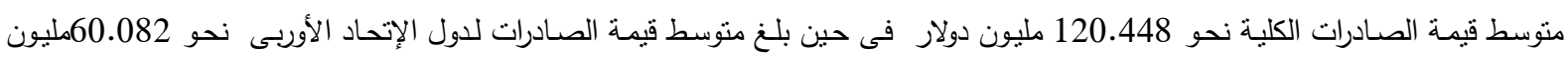

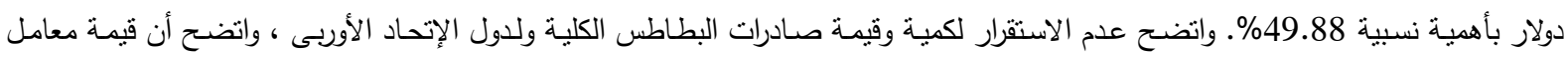

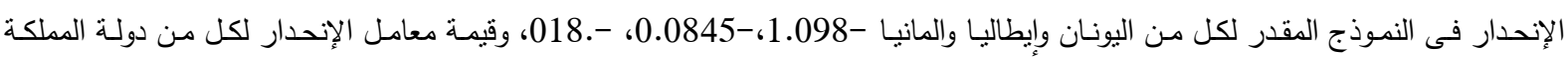

المتحدة وهولندا 0.107، 0.258 .

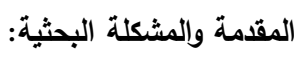

تعد قضية تتمية الصادرات المصرية من القضايا المحورية الهامة لإعتماد عملية التتمية الثاملة والمستدامة بشكل كيبر على التدفقات

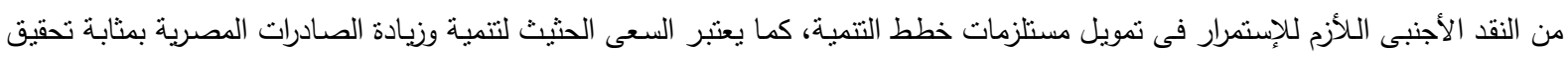

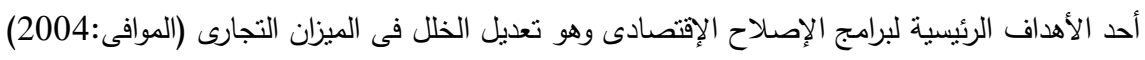

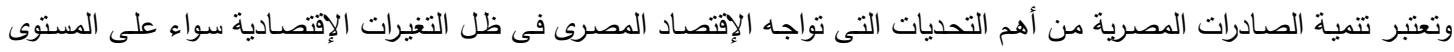

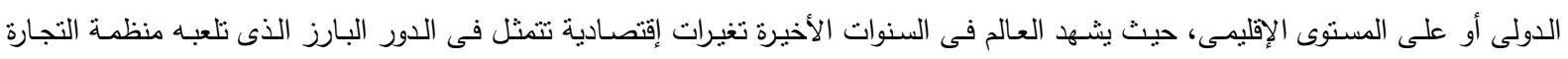

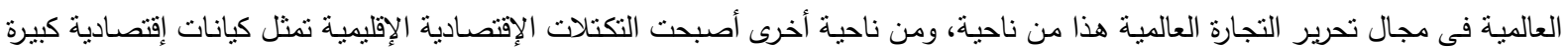

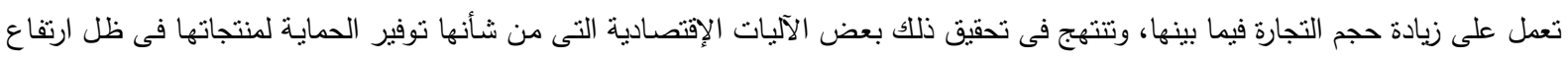

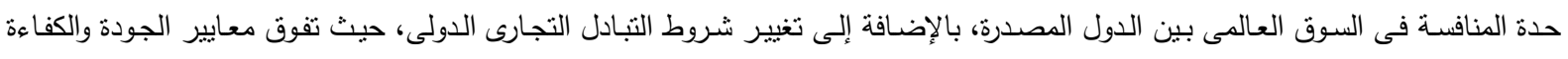

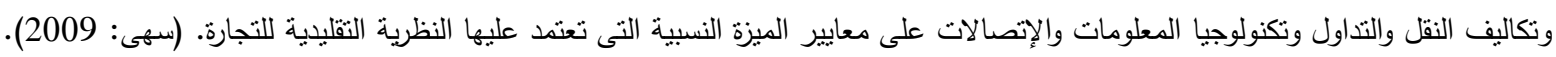

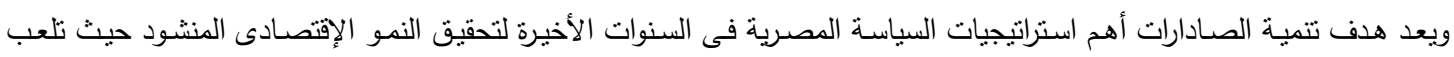

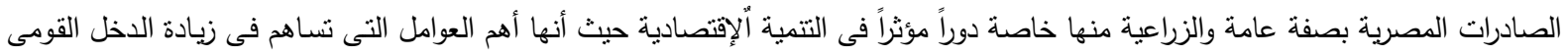

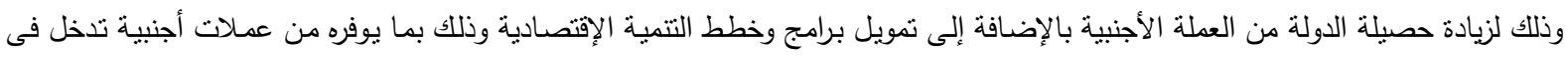
الإنتثمارات الجديدة (داليا:2008). 
كما يرتبط أمر تتمية الصسادرات الزراعية إرتباطاً وثيقا بالأحداث والتغيرات العالمية ولذلك فإن تحقيق اهتمام متزايد ومناخ تصديرى أفضل يساهم فى زيادة قدرة تلك الصادرات على النفاذ للأسواق الخارجية وذلك من خلال زيادة قدرتها التنافسية والجودة العالية وتميز المنتجات وإبتكار

منتجات جديدة (الملاح:2004) وتعتبر البطاطس من محاصيل الخضر الرئيسية فى مصر وتأنى فى المرتبة الثانية بعد الطماطم من حيث المساحة، ولكنها تعتبر محصول الخضر الأول تصديرياً ومتوسط إستهلاك الفرد سنويا من البطاطس فى مصر حوالى 25 كجم، وتزرع البطاطس على عروتين رئيسيتين هما العروة الصيفية والعروة النيلية وهناك أكثر من صنف من البطاطس يفضل البعض منها في الطهى والبعض الأخر فى التصنيع، وقد بلغ التغ متوسط المساحة المزروعة من البطاطس فى العروتين نحو 200.75 ألف فدان وذلك خلال الفترة (1990-2013)، كما بلغ متوسط الإنتاج الكلى نحو 25 مليون طن سنويا تكفى الإستهلاك المحلى ويتم تصدير نحو 350 ألف طن يذهب منها إلى دول الإتحاد الأوربى مابين (200250) ألف طن (وزارة الزراعة واستصلاح الأراضى: 2013) وعلى الرغم من أهمية دول الإتحاد الأوربى كسوق تصديرى لمحصول البطاطس إلا أنه لوحظ فى الفترة الأخيرة تراجع كمية صادرات

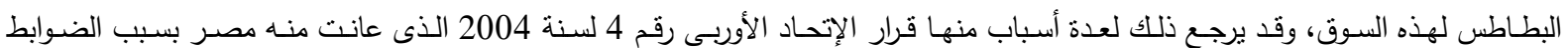

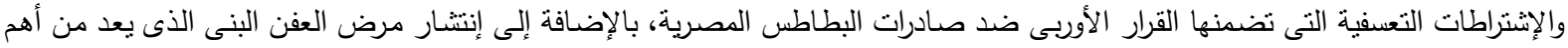

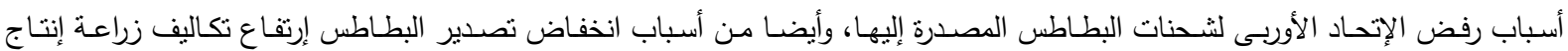
محصول البطاطس وابتعاد الدولة عن دعم المزارعين في شراء تقاوي البطاطس المستوردة وذلك منذ عام 2005، مما جعل المزارعين يستخدمون

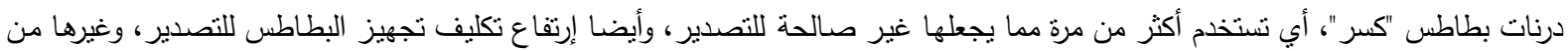

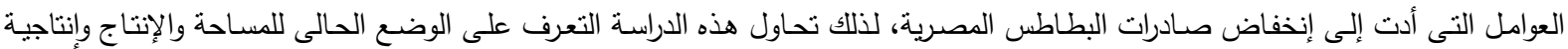

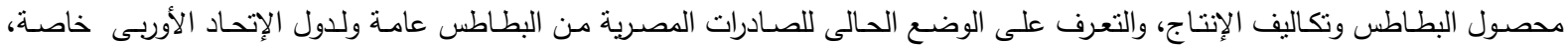
والتعرف على مدى الاستقرار الإقتصادى لهذه الصادرات والتعرف على العوامل المؤثرة على الطلب على صادرات البطاطس لدول الإتحاد الأوربى.

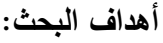

يستهف هذا البحث التعرف على الوضع الراهن لتصدير محصول البطاطس فى السوق المصرى إلى دول الإتحاد الأوربى ومدى تحقيق

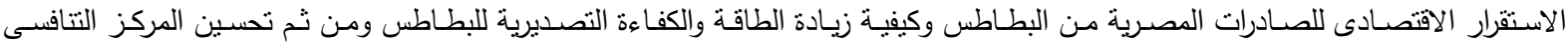
للصادرات الدصرية من البطاطس عامة إلى دول الإتحاد الأوربى خاصة. ولتحقيق هذا الهلف تم دراسة الأهداف الفرعية الآتية:

1- تقدير الإتجاه الزمنى العام لكل من المساحة والإنتاج وتكاليف الإنتاج لمحصول البطاطس فى مصر خلال الفترة (1999-2014). 2- تقدير الأهمية النسبية لكمية صادرات مصر من البطاطس لدول الإتحاد الأوربى بالنسبة إلى صادرات مصر الكلية من البطاطس خلال الفترة (1999-2014). 3- تقدير الأهمية النسبية لقيمة صادرات مصر من البطاطس لدول الإتحاد الأوربى بالنسبة إلى صادرات مصر الكلية من البطاطس خلال الفترة (1999-2014). 4- دراسة التزيع الجغرافى لكمية وقيمة صعادرات مصر من البطاطس لأهم دول دول الإتحاد الأوربى خلال الفنرة (1994-1994-2014). 5- دراسة الإستقرار الاقتصادى لمحصول البطاطس خلال الفترة (1999-2014).

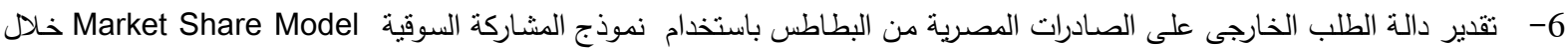
الفترة (1999-2014).

مصادر البيانات والطريقة البحثية إعتمد البحث على البيانات الثانوية المنشورة وغير المنشورة، والصادرة من كل من الجهاز المركزي للتعبئة العامة والإحصاء وقاعدة بيانات

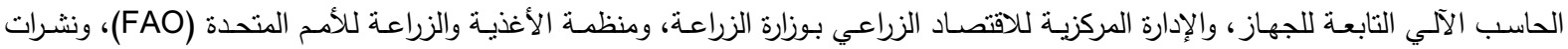

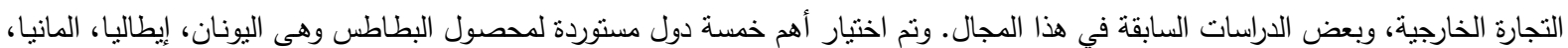
انجلترا، وهولندا ولتحقيق أهداف البحث تم استخدام أساليب النحليل الإحصائي والاقتصادى والقياسى من خلال تقدير نماذج الإتجاه العام وأهمها النموذج

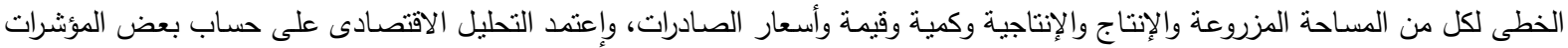

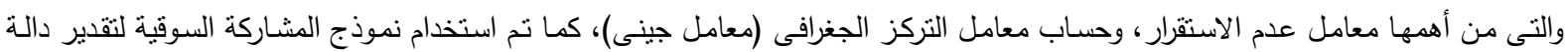
الطلب على صادرات البطاطس من اهن 
النتائج البحثية ومناقشتها

أولا- تطور مساحة وإنتاج وتكاليف إنتاج محصول البطاطس خلال الفترة (1999-2014) بدراسة تطور مساحة محصول البطاطس يتضـح من جدول (1) أن منتوسط مساحة محصول البطاطس على مستوى الجمهورية خلال الفترة

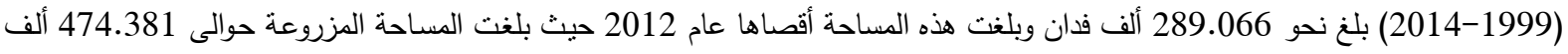

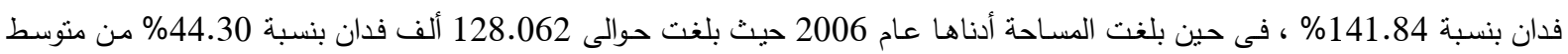

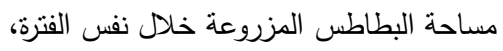
كما يتبين من معادلة الإتجاه الزمنى العام لمساحة البطاطس بجدول (2) وجود تزايد معنوى إحصائيا عند مستوى معنوية 0.01 بمعدل سنوى

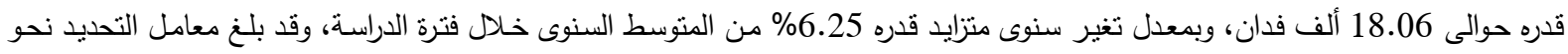
0.6875 أى أن عنصر الزمن بما يتضمنه من متغيرات يفسر نحو 63.75\% من التغيرات فى المساحة المزروعة من محصول البطاطس والباقى فئى يمثل 31.25\% يرجع لعوامل أخرى غير مدروسة. وبدراسة نطور إنتاج البطاطس يتضـح من جدول 1 أن منوسط الإتتاج لمحصول البطاطس على مستوى الجمهوريـة خلال الفترة (1999-

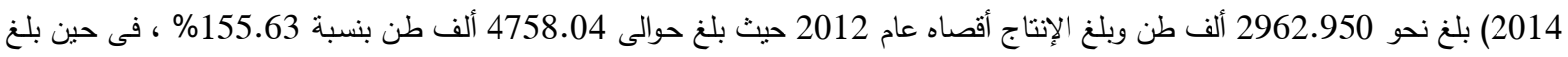
الإنتاج أدناه عام 2006 حيث بلغ حوالى نكو 1403.429 ألف طن بنسبة 47.37\% من منوسط إنتاج البطاطس خلال نفس الفترة. كما يتبين من معادلة الإتجاه الزمنى العام لإنتاج البطاطس بجدول (2) وجود تزايد معنوى إحصائيا عند مستوى معنوية 0.01 بمعدل سنوى معن قدره حوالى 218.88 ألف طن، وبمعدل تغير سنوى منزايد قدره 7.39\% من المتوسط السنوى خلال فترة الدراسة، وقد بلغ معامل التحديد نحو

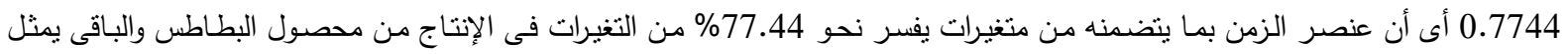
22.56 يرجع لعوامل أخرى غير مدروسة.

وبدراسة تطور تكاليف إنتاج محصول البطاطس بتضح من جدول (1) أن منوسط تكاليف إنتاج فدان البطاطس على مستوى الجمهورية خلص

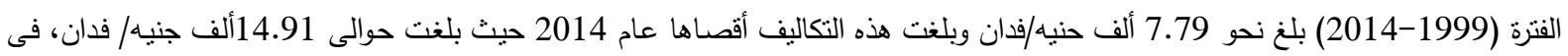
حين بلغت التكاليف أدناها عام 2001 حيث بلغت حوالى 3.61 ألف جنيه/فدان. كما يتبين من معادلة الإتجاه الزمنى العام لتكاليف إنتاج البطاطس بجدول (2) وجود تزايد معنوى إحصائيا عند مستوى معنوية 0.01 بمعدل

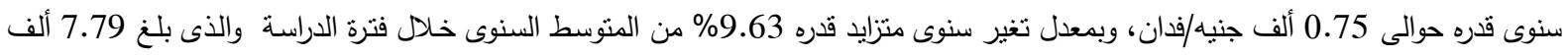
جنيه، وقد بلغ معامل التحديد نحو 0.9508 أى أن عنصر الزمن بما يتضمنه من متغيرات يفسر نحو

محصول البطاطس والباقى يمثل 4.92\% برجع معامل لعوامل أخرى غير مدروسة.

جدول (1) تطور مساحة وانتاج وتكاليف إنتاج محصول البطاطس في مصر خلال الفترة (1999-2014)

\begin{tabular}{|c|c|c|c|c|c|c|}
\hline \multicolumn{2}{|c|}{ تكاليف إنتاج الفدان } & \multicolumn{2}{|c|}{ الإنتاج } & \multicolumn{2}{|c|}{ مساحة البطاطس } & \multirow{2}{*}{ السنوات } \\
\hline$\%$ & ألف جنيه/فدان & $\%$ & الكمية (ألف طن) & $\%$ & المساحة (ألف فدان) & \\
\hline 49.42 & 3.85 & 67.15 & 1989.8 & 70.34 & 203.32 & 1999 \\
\hline 43.39 & 3.38 & 60.04 & 1778.9 & 72.49 & 209.55 & 2000 \\
\hline 46.34 & 3.61 & 66.90 & 1982.3 & 71.52 & 206.75 & 2001 \\
\hline 47.88 & 3.73 & 67.00 & 1985.3 & 68.03 & 196.64 & 2002 \\
\hline 57.77 & 4.50 & 75.71 & 2243.3 & 75.06 & 216.98 & 2003 \\
\hline 77.28 & 6.02 & 71.67 & 2123.5 & 85.81 & 248.04 & 2004 \\
\hline 81.51 & 6.35 & 56.76 & 1681.7 & 68.71 & 198.62 & 2005 \\
\hline 89.99 & 7.01 & 47.37 & 1403.4 & 44.30 & 128.06 & 2006 \\
\hline 102.82 & 8.01 & 113.05 & 3349.8 & 110.36 & 319.03 & 2007 \\
\hline 109.24 & 8.51 & 120.39 & 3567.1 & 113.27 & 327.42 & 2008 \\
\hline 120.67 & 9.40 & 123.50 & 3659.3 & 114.06 & 329.72 & 2009 \\
\hline 121.82 & 9.49 & 122.65 & 3634.2 & 115.77 & 334.64 & 2010 \\
\hline 128.11 & 9.98 & 146.42 & 4338.4 & 152.52 & 440.9 & 2011 \\
\hline 157.89 & 12.3 & 160.58 & 4758.0 & 164.11 & 474.38 & 2012 \\
\hline 173.43 & 13.51 & 145.15 & 4300.9 & 131.80 & 381.00 & 2013 \\
\hline 191.40 & 14.91 & 155.63 & 4611.3 & 141.84 & 410.00 & 2014 \\
\hline 100.00 & 7.79 & 100.00 & 2963 & 100.00 & 289.07 & المتوسط \\
\hline
\end{tabular}


جدول (2) معادلات الإتجاه الزمنى العام للمساحة، والإنتاج، وتكاليف إنتاج لمحصول البطاطس فى مصر خلال الفترة (1999-2014)

\begin{tabular}{|c|c|c|c|c|c|}
\hline$F_{c}$ & $\mathrm{R}^{2}$ & معدل التغير & المنوسط & المعادلة & التنغير \\
\hline$* * 34.01$ & 0.6875 & $\% 6.25$ & 289.066 & 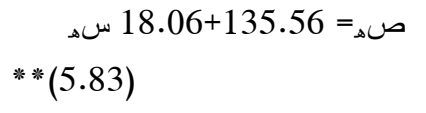 & (ألف فداحة) \\
\hline$* * 52.48$ & 0.7744 & $\% 7.39$ & 2962.950 & $\begin{array}{l}\text { صهA } 218.88+1102.47 \text { سه } \\
* * * 24)\end{array}$ & 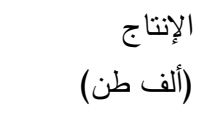 \\
\hline$* * 270.45$ & 0.9508 & $\% 9.63$ & 7.79 & $\begin{array}{l}\text { صه = } 1.43 \text { +0.75 سهـ } \\
*(16.45)\end{array}$ & (ألف جنيه/فاليف الإنتاج) \\
\hline
\end{tabular}

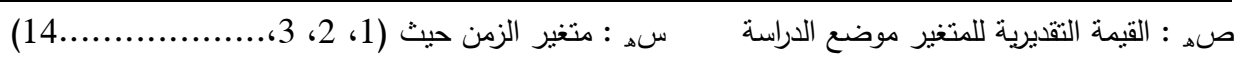

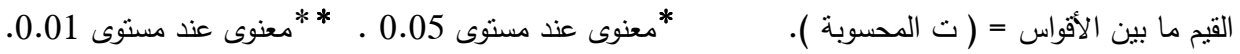

ثانيا: الأهمية النسبية لكمية صادرات مصر من البطاطس لاول الإتحاد الأوربى خلال الفترة (1999-2014) بدراسة تطور كمية الصادرات الكلية من البطاطس يتضح من جدول (3) أن منوسط كمية صادرات محصول البطاطس خلال الفترة (19992014) بلغت نحو 361.3289 ألف طن وبلغت كمية الصادرات أقصاها عام 2014 حيث بلغت الكمية المصدرة حوالى 193.

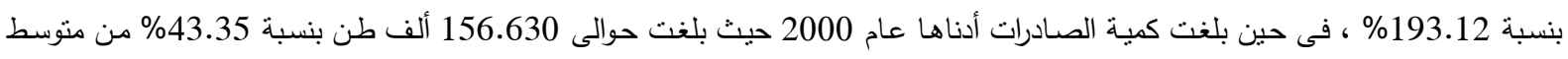
صادرات محصول البطاطس خلال نفس الفترة . جدول (3) تطور الأهمية النسبية لكمية صـادرات مصر من البطاطس لدول الإتحاد الأوربى بالنسبة إلى صادرات مصر الكلية من البطاطس

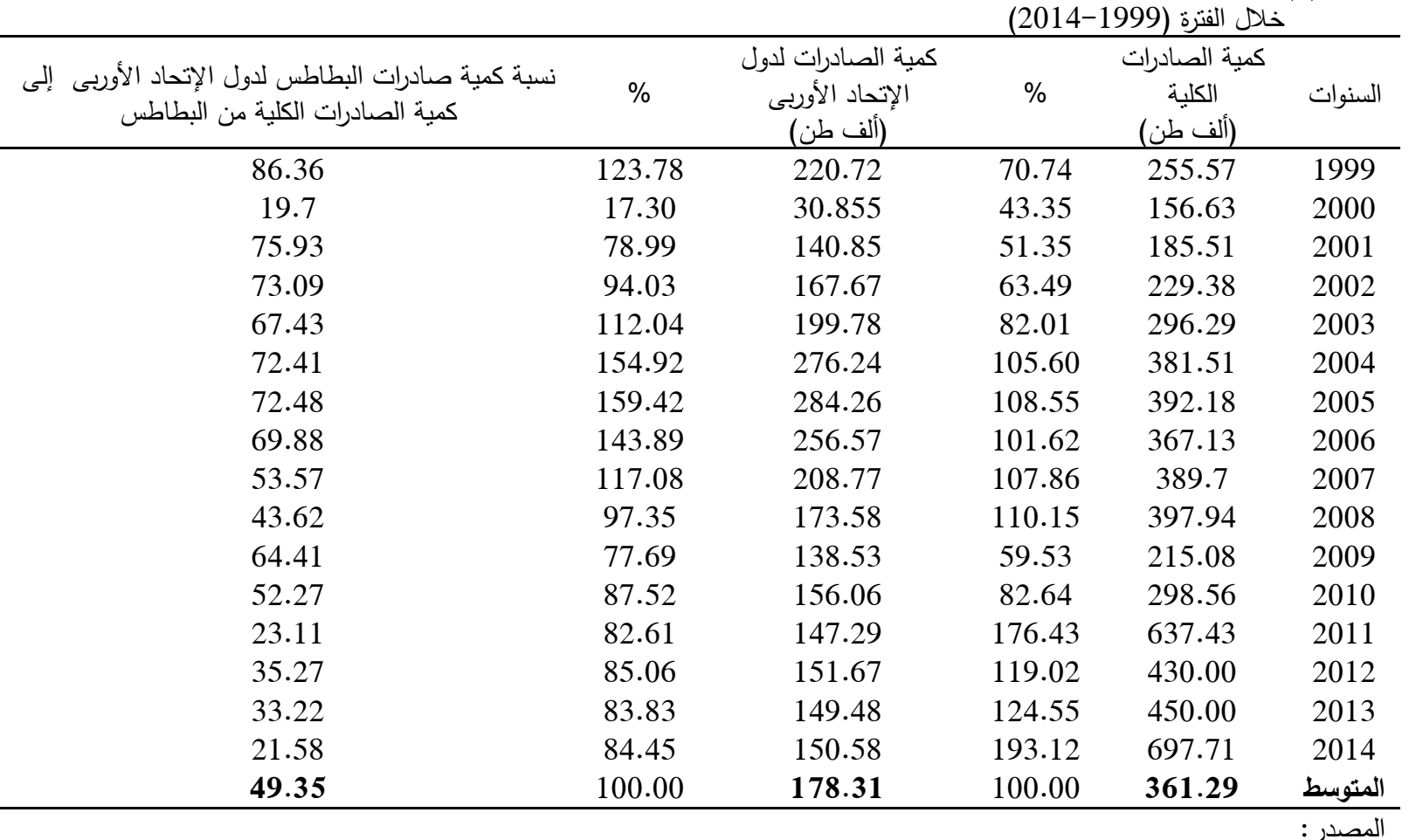
منظمة الأغذية والزراعة وزارة الزراعة واستصلاح الأراضي ، قطاع الثئون الإقتصادية

كما يتبين من معادلة الإتجاه الزمنى العام لكميـة صـادرات البطاطس بجدول (4) وجود تزايد معنوى إحصـائيا عند مستوى معنويـة 0.01

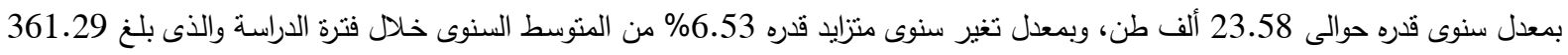

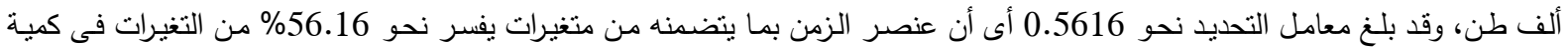
الصادرات من البطاطس والباقى يمنل 43.84\% يرجع لعوامل أخرى غير مدروسة. 
وبدراسة تطور كمية صادرات مصر من البطاطس لدول الإتحاد الأوربى يتضح من جدول (3) أن منوسط كمية صادرات محصول البطاطس

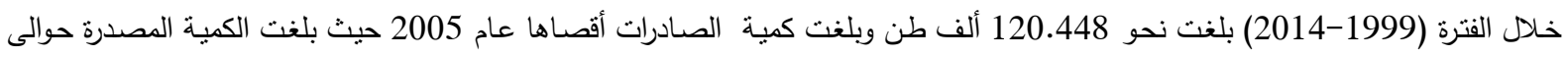

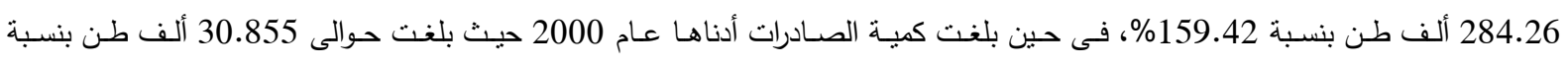
17.30\% من منوسط صادرات محصول البطاطس خلال نفس الفترة.

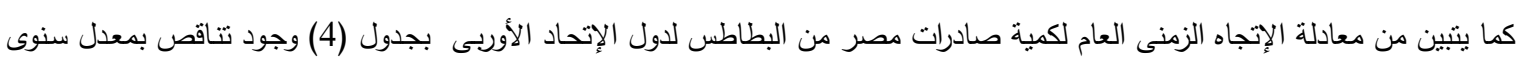

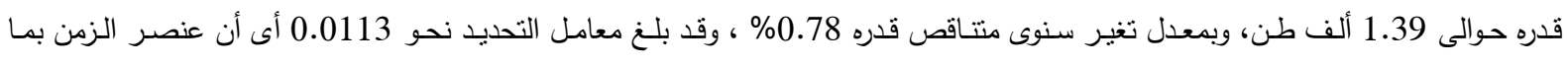

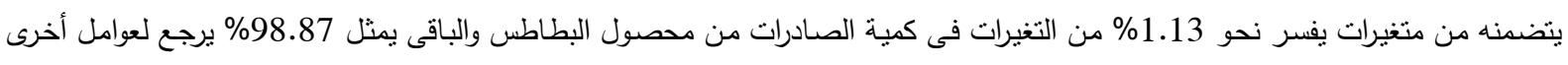
غير مدروسة.

وبدراسة تطور الأهمية النسبية لكمية صادرات مصر من البطاطس لدول الإتحاد الأوربى بالنسبة إلى صادرات مصر الكلية من البطاطس

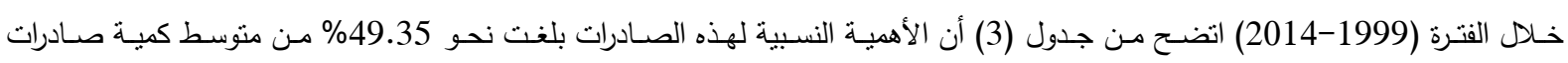
البطاطس ، وبلغت هذه الأهمية أقصاها عام 1999 حيث بلغت 86.36\%، في حين بلغت أدناها عام 2014 حيث بلغت نحو 21.58\%

جدول(4) معادلات الإتجاه الزمنى العام لكمية الصادرات المصرية الكلية والصادرات لدول الإتحاد الأوربى من محصول البطاطس خلال الفترة

\begin{tabular}{|c|c|c|c|c|c|}
\hline & & & & & $(2014-1999)$ \\
\hline \multirow{2}{*}{$\mathrm{Fc}$} & \multirow{2}{*}{$\mathrm{R}^{2}$} & معدل التغير & & \multirow{2}{*}{ المعادلة } & 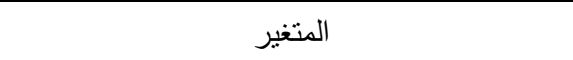 \\
\hline & & السنوى \% & 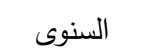 & & 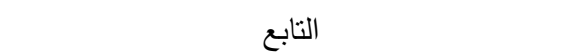 \\
\hline \multirow{2}{*}{ **17.97 } & \multirow{2}{*}{0.5616} & \multirow{2}{*}{$\% 6.53$} & \multirow{2}{*}{361.289} & صه= 160.89+23.58 سه & كمية الصادرات الكلية \\
\hline & & & & $* *(4.24)$ & من البطاطس(طن) \\
\hline 0.159 & 0.0113 & $\% 0.78$ & 178.305 & صن= = 1.39-190.16 سه & كمية الصادرات الكلية من البطاطس للسوق الأوربية \\
\hline
\end{tabular}

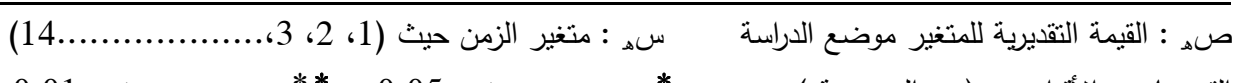

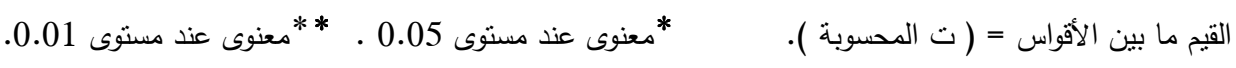

ثالثا: الأهمية النسبية لقيمة صادرات مصر من البطاطس لدول الإتحاد الأوربى خلال الفترة (1999-2014)

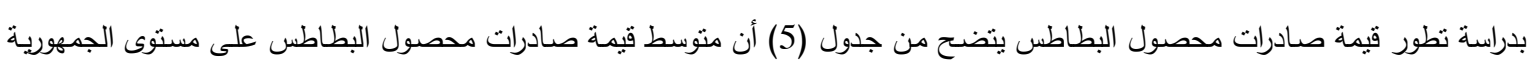

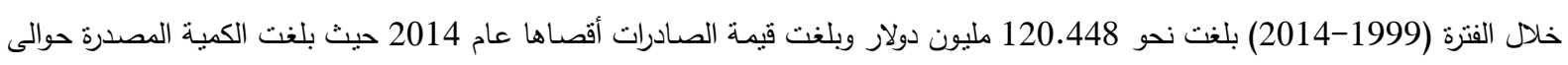

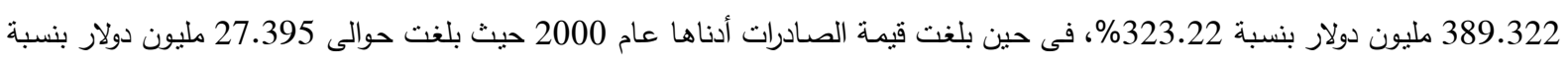
22.74\% من منوسط صادرات محصول البطاطس خلال نفس الفترة،

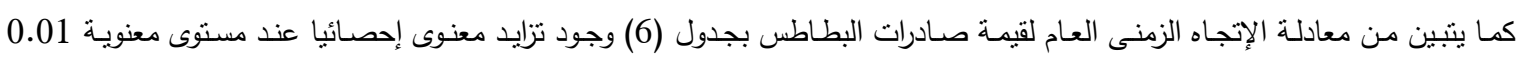

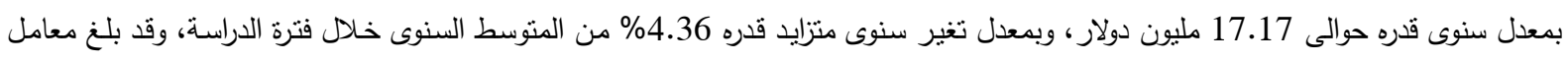

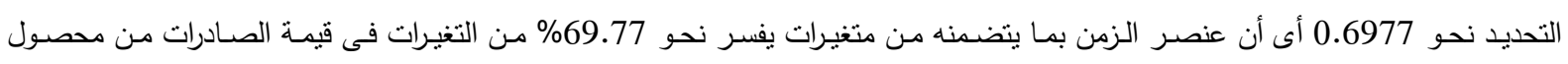
البطاطس والباقى يمثل 30.23\% يرجع لعوامل أخرى غير مدروسة.

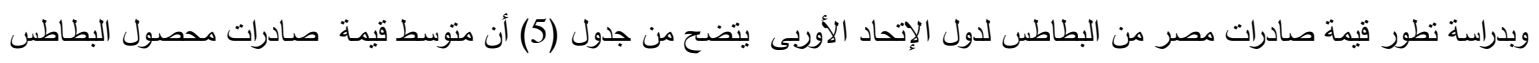

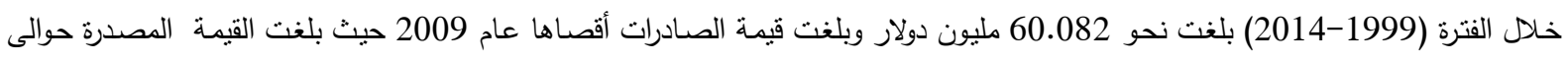

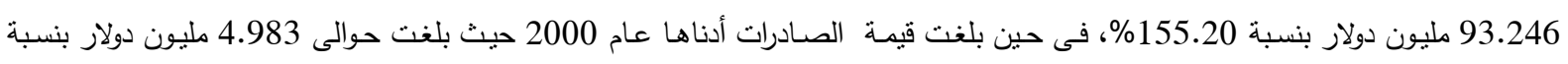
8.29 من منوسط صادرات محصول البطاطس خلال نفس الفترة.

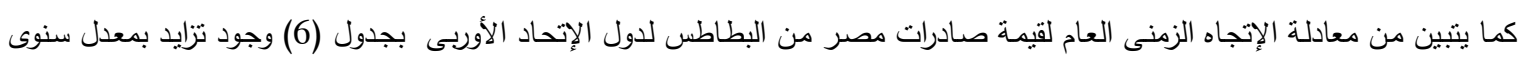

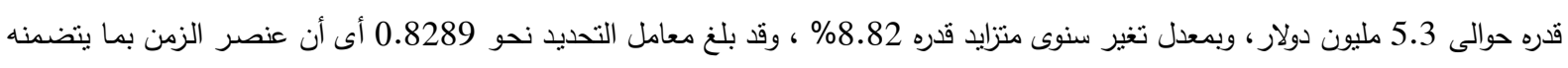

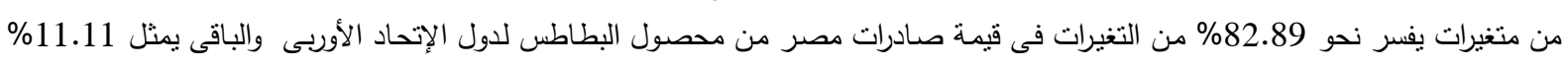
يرجع لعوامل أخرى غير مدروسة. 
وبدراسـة تطور الأهميـة النسبية لقيمـة صـادرات مصـر من البطاطس لدول الإتحاد الأوربى بالنسبة إلى قيمـة صـادرات مصـر الكليـة من البطاطس خلال الفترة (1999-2014) اتضـح من جدول (5) أن منوسط الأهمية النسبية لهذه الصادرات بلغ نحو 49.88\% من بلهية إجمالى قيمة صادرات البطاطس المصرية، وبلغت هذه الأهمية أقصاها عام 2009 حيث بلغت 67.10\%، فى حين بلغت أدناها عام 2000 حيث بلغت نحو 18.19\%، مما يعكس تراجع صـادرات مصر من البطاطس إلى دول الإتحاد الأوربى فى السنوات الأخيرة نتيجة إنتشـار مرض العفن البنى فى البطاطس ووضع الإتحاورد الأوربى إثتراطات وقيود على الصادرات المصرية من البطاطس.

جدول (5) تطور الأهمية النسبية لقيمة صادرات مصر من البطاطس لدول الإتحاد الأوربى بالنسبة إلى صادرات مصر الكلية من البطاطس خلا الفترة (1999-2014)

\begin{tabular}{|c|c|c|c|c|c|}
\hline نسبة قيمة صادرات البطاطس لدول الإلى قليمة الصادرات الكلية من البطاد & $\%$ & 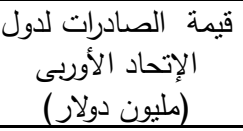 & $\%$ & 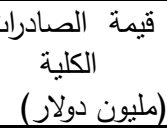 & السنوات \\
\hline 91.00 & 69.68 & 41.863 & 38.19 & 46.002 & 1999 \\
\hline 18.19 & 8.29 & 4.983 & 22.74 & 27.395 & 2000 \\
\hline 78.52 & 38.89 & 23.363 & 24.70 & 29.755 & 2001 \\
\hline 76.85 & 54.51 & 32.752 & 35.38 & 42.619 & 2002 \\
\hline 72.69 & 53.20 & 31.961 & 36.50 & 43.969 & 2003 \\
\hline 75.10 & 84.02 & 50.481 & 55.81 & 67.222 & 2004 \\
\hline 79.9 & 103.01 & 61.889 & 64.30 & 77.455 & 2005 \\
\hline 75.10 & 81.69 & 49.08 & 54.25 & 65.35 & 2006 \\
\hline 54.9 & 98.79 & 59.353 & 89.75 & 108.1 & 2007 \\
\hline 43.32 & 126.99 & 76.298 & 146.23 & 176.13 & 2008 \\
\hline 67.10 & 155.20 & 93.246 & 115.37 & 138.96 & 2009 \\
\hline 65.42 & 141.09 & 84.772 & 107.57 & 129.57 & 2010 \\
\hline 35.53 & 148.15 & 89.009 & 207.98 & 250.51 & 2011 \\
\hline 56.13 & 144.62 & 86.891 & 128.52 & 154.8 & 2012 \\
\hline 48.86 & 146.38 & 87.95 & 149.44 & 180 & 2013 \\
\hline 22.45 & 145.50 & 87.42 & 323.22 & 389.32 & 2014 \\
\hline 49.88 & 100.00 & 60.082 & 100.00 & 120.45 & المتوسط \\
\hline
\end{tabular}

منظمة الأغذية والزراعة وزارة الزراعة واستصلاح الأراضي ، قطاع الثئون الإقتصادية جدول(6) معادلات الإتجاه الزمنى العام لقيمة الصـادرات المصرية الكلية والصادرات لدول الإتحاد الأوربى من محصول البطاطس خلال الفترة

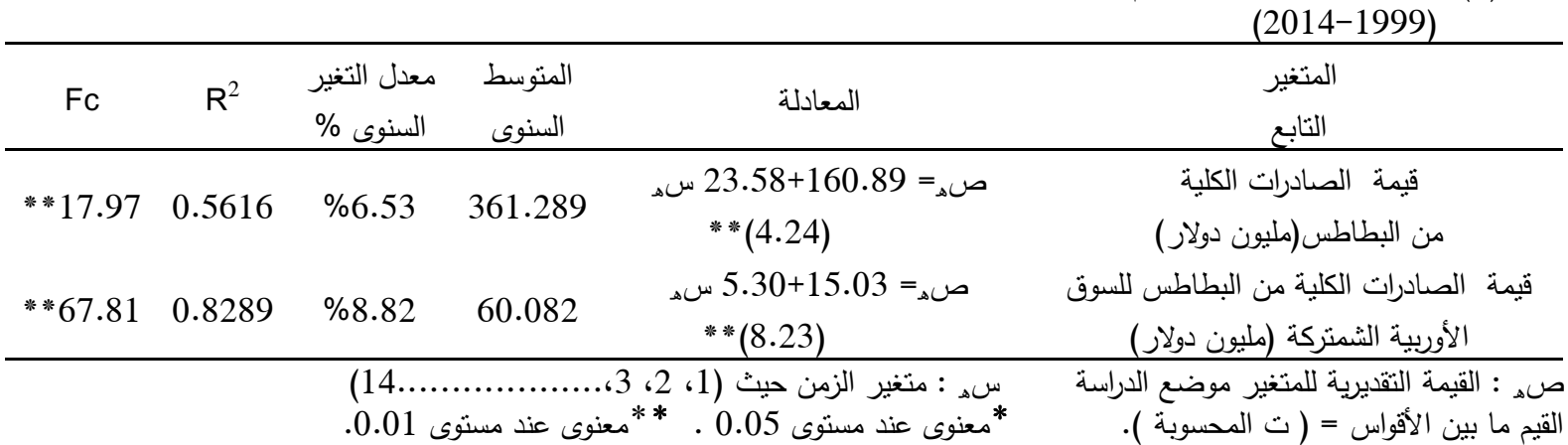


رابعاً: التوزيع الجغرافى لكمية وقيمة صادرات مصر من البطاطس لأهم دول دول الإتحاد الأوربى خلال الفترة (1999-2014) بدراسة التوزيع الجغرافي لكمية وقيمة صـادرات مصر من محصول البطاطس إلى السوق الأوبية المشركة خلال الفترة (1999-2014)

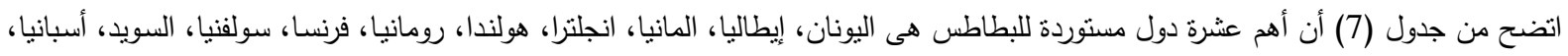

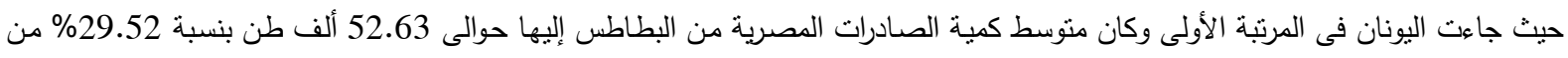

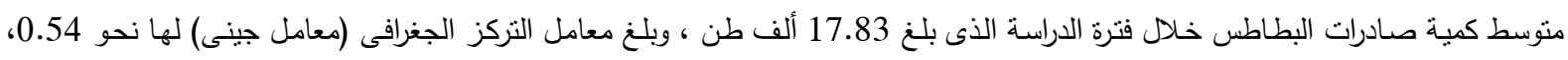

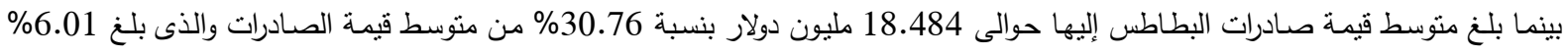

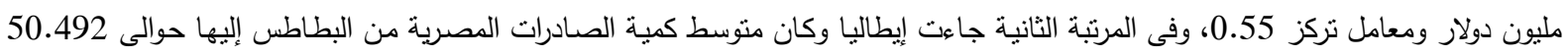

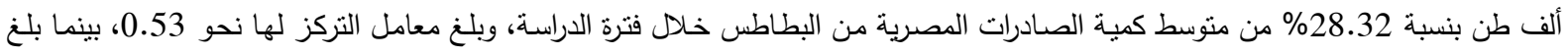

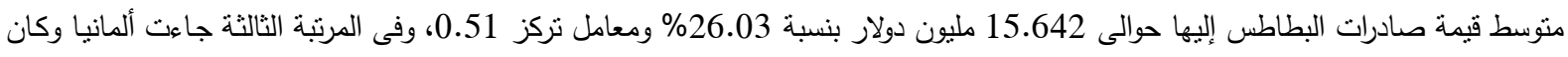

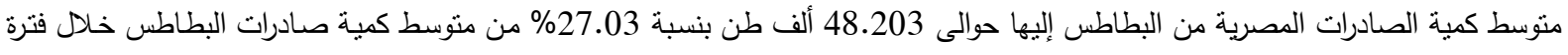

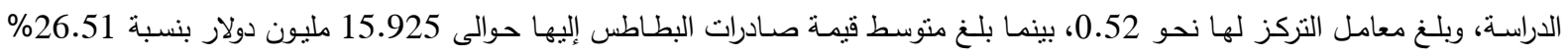

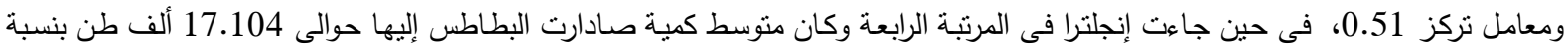

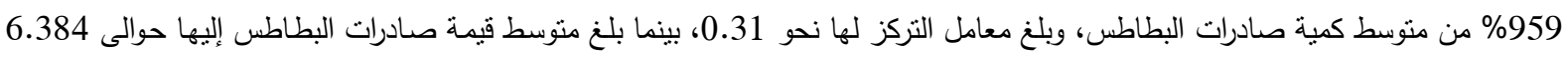

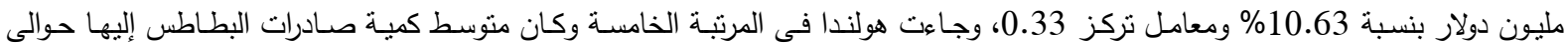

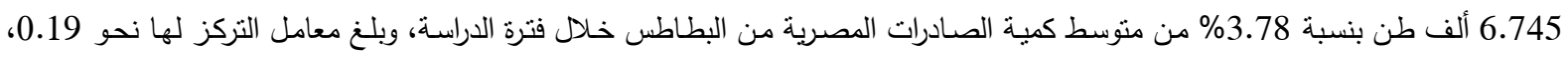

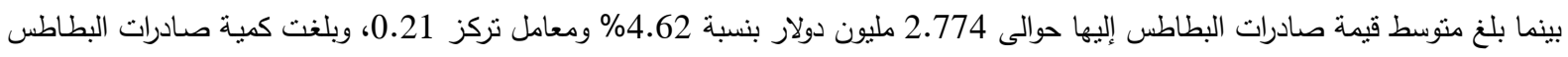

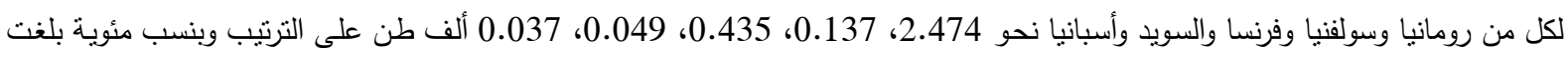

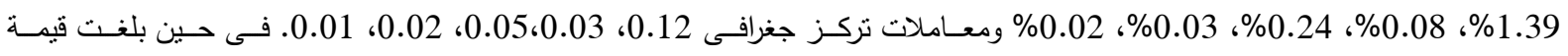

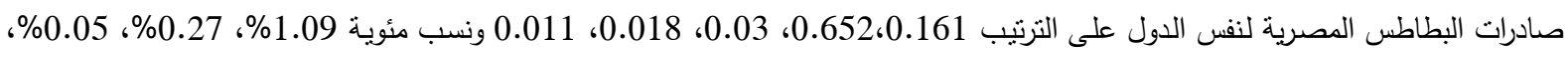

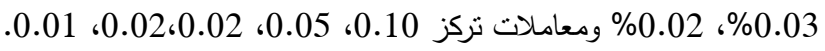

ويتضح مما سبق أن أهم خمسة دول مستوردة للبطاطس المصرية فى دول الإتحاد الأوربى هى اليونان وإيطاليا وألمانيا، وانجلترا، وهولندا

جدول (7) التوزيع الجغرافى لكمية وقيمة صادرات مصر من البطاطس لأهم دول دول الإتحاد الأوربى خلال الفترة (1999-2014)

\begin{tabular}{|c|c|c|c|c|c|c|}
\hline معامل جينى & (\%) & متوسط قيمة الصادرات & (معامل التزكز) & (\%) & متوسط كمية الصادرات & الدول \\
\hline 0.55 & 30.76 & 18.484 & 0.54 & 29.52 & 52.630 & اليونان \\
\hline 0.51 & 26.03 & 15.642 & 0.53 & 28.32 & 50.492 & إيطاليا \\
\hline 0.51 & 26.51 & 15.925 & 0.52 & 27.03 & 48.203 & المانيا \\
\hline 0.33 & 10.63 & 6.384 & 0.31 & 9.59 & 17.104 & انجلترا \\
\hline 0.21 & 4.62 & 2.774 & 0.19 & 3.78 & 6.745 & هولندا \\
\hline 0.10 & 1.09 & 0.652 & 0.12 & 1.39 & 2.474 & رومانيا \\
\hline 0.05 & 0.27 & 0.161 & 0.05 & 0.24 & 0.435 & سولفنيا \\
\hline 0.02 & 0.05 & 0.030 & 0.03 & 0.08 & 0.137 & فرنسا \\
\hline 0.02 & 0.03 & 0.018 & 0.02 & 0.03 & 0.049 & السويد \\
\hline 0.01 & 0.02 & 0.011 & 0.01 & 0.02 & 0.037 & اسبانيا \\
\hline 0.23 & 10.00 & 6.01 & 0.23 & & 17.83 & الرنوسط \\
\hline
\end{tabular}

المصدر: حسبت من الجهاز المركزى للتعبئة العامة والإحصاء ، مركز المعلومات ودعم اتخاذ القرار ، قاعدة بيانات التجارة الخارجية ، القاهرة.)

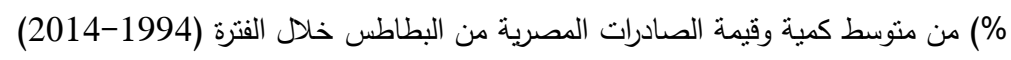

خامساً: الإستقرار الاقتصادى لمحصول البطاطس خلال الفترة (1999-2014)

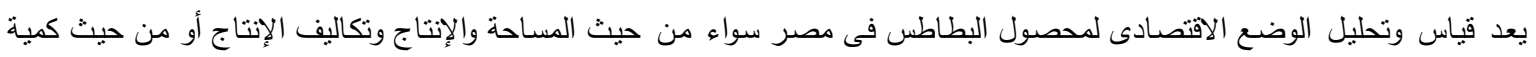

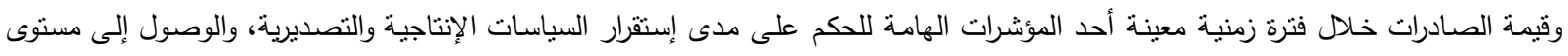

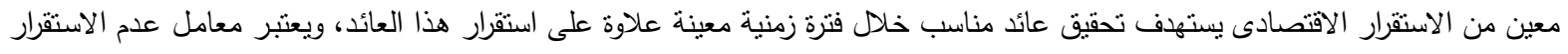


من المؤشرات الهامة النى تقيس التذبذب فى إنتاج وصادرات السلع المختلفة التى منها البطاطس، حيث أن معامل عدم الإستقرار عبارة عن

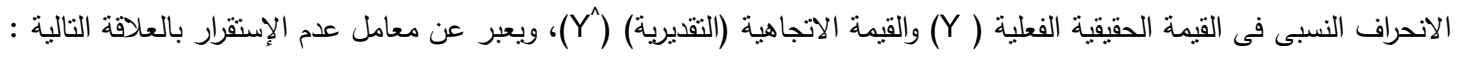

$$
N . S=\frac{\left|Y_{t}-Y^{\wedge}{ }_{t}\right|}{Y^{\wedge}{ }_{t}} x 100
$$

N.S

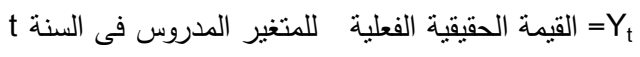
القيمة الإتجاهية (التقديرية) المقدرة من معادلة الإتجاه الزمنى العام للظاهرة المدروسة فئة

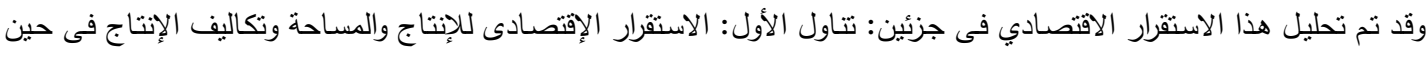

تناول الثانى الاستقرار الاقتصادى للصادرات (كمية وقيمة)

أولا: الإستقرار الاقتصادى لمحصول البطاطس من حيث (المساحة والإنتاج وتكاليف الإنتاج) خلال الفترة (1999-2014):

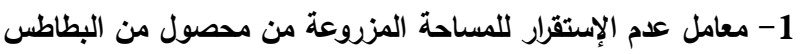

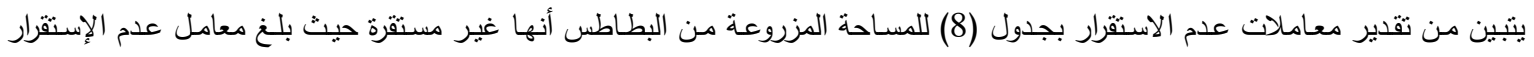

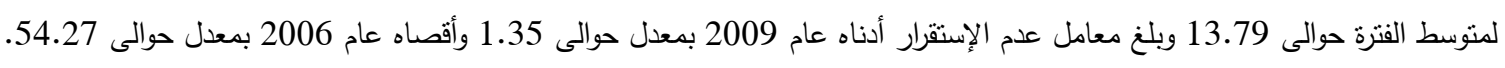
2-2 معامل عدم الإستقرار لإنتاج محصول البطاطس

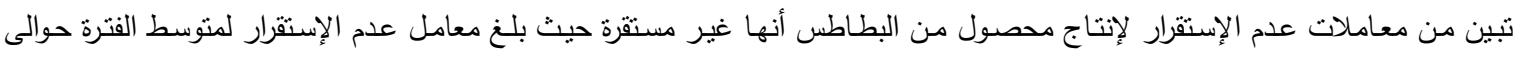

14.42 وبلغ معامل عدم الاستقرار أدناه عام 2002 بمعدل حوالى 0.37 وأقصاه عام 2006 بمعدل حوالى 50.82

3- 3 معامل عدم الإستقرار لتكاليف إنتاج محصول البطاطس

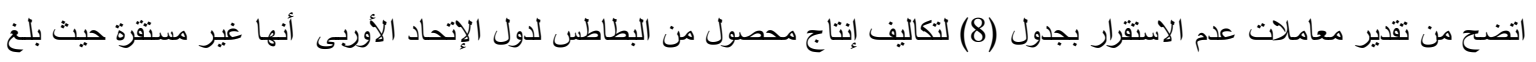

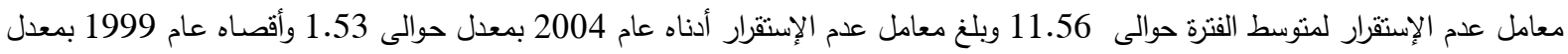

حوالى 76.80

جدول (8) معاملات عدم الإنتقرار لمحصول البطاطس من حيث (المساحة والإنتاج ونكاليف الإنتاج) خلال الفترة (1999-2014).

\begin{tabular}{|c|c|c|c|}
\hline معامل عدم الإستقرار لنكاليف إنتاج البطاطس & معامل عدم الإستقرار لإنتاج البطاطس & معامل عدم الإستقرار لكساحة البطاطس & 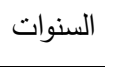 \\
\hline 76.80 & 50.59 & 32.35 & 1999 \\
\hline 15.28 & 15.49 & 22.06 & 2000 \\
\hline 1.90 & 12.69 & 8.97 & 2001 \\
\hline 15.76 & 0.37 & 5.37 & 2002 \\
\hline 13.05 & 2.11 & 3.93 & 2003 \\
\hline 1.53 & 12.10 & 1.69 & 2004 \\
\hline 4.91 & 36.17 & 24.19 & 2005 \\
\hline 5.65 & 50.82 & 54.27 & 2006 \\
\hline 2.03 & 9.03 & 7.02 & 2007 \\
\hline 4.68 & 8.38 & 3.56 & 2008 \\
\hline 2.92 & 4.25 & 1.35 & 2009 \\
\hline 9.00 & 2.54 & 5.01 & 2010 \\
\hline 10.73 & 9.89 & 19.05 & 2011 \\
\hline 3.12 & 14.19 & 22.14 & 2012 \\
\hline 6.52 & 1.93 & 6.26 & 2013 \\
\hline 11.01 & 0.15 & 3.42 & 2014 \\
\hline 11.56 & 14.42 & 13.79 & المتوسط \\
\hline
\end{tabular}

ثانيا:الإستقرار الاقتصادى لمحصول البطاطس من حيث (كمية وقيمة خلال الفترة (1999-2014): 1- 1 - معامل عدم الإستقرار لكمية الصادرات الكلية من البطاطس

يتبين من تقدير معاملات عدم الاستقرار بجدول (9) لكمية الصادرات الكلية من البطاطس أنها غير مستقرة حيث بلغ معامل عدم الإستقرار

لمتوسط الفترة حوالى 0.36وبلغ معامل عدم الإستقرار أدناه عام 2008 بمعدل حوالى 0.32 وأقصاه عام 1999 بمعدل حوالى 38.54. 
2- معامل عدم الإستقرار لقيمة الصادرات الكلية من البطاطس

تبين من معاملات عدم الإستقرار لقيمة الصادرات الكلية من البطاطس أنها غير مستقرة حيث بلغ معامل عدم الإستقرار لمتوسط الفترة حوالى

34.70 وبلغ معامل عدم الاستقرار أدناه عام 2011 بمعدل حوالى 0.72 وأقصاه عام 2001 بمعدل حوالى 61.37.

3- معامل عدم الإستقرار لكمية الصادرات من البطاطس إلى السوق الأوربية المشتركة

اتضح من تقدير معاملات عدم الاستقرار بجدول (9) لكمية الصادرات المصرية من البطاطس لدول الإتحاد الأوربى أنها غير مستقرة حيث بلغ معامل عدم الإستقرار لمتوسط الفترة حوالى 0.28 وبلغ معامل عدم الإستقرار أدناه عام 2003 بمعدل حوالى 0.01 وأقصاه عام 2000 بمعدل حوالى 0.84.

4- معامل عدم الإستقرار لكمية الصادرات من البطاطس إلى السوق الأوربية المشتركة اتضـح أن معاملات عدم الإستقرار لقيمة الصـادرات المصرية من البطاطس لدول الإتحاد الأوربى أنها غير مستقرة حيث بلغ معامل عدم

الإستقرار لمتوسط الفترة حوالى 0.23 وبلغ معامل عدم الاستقرار أدناه عام2012 بمعدل حوالى 0.03 وأقصاه عام 999 بمعدل حوالى 1.06

جدول (9) معاملات عدم الإستقرار لصادرات الكلية من البطاطس وصادراتها إلى دول الإتحاد الأوربى خلال الفترة (1999-2014)

\begin{tabular}{|c|c|c|c|c|}
\hline 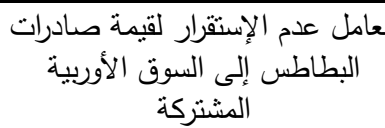 & 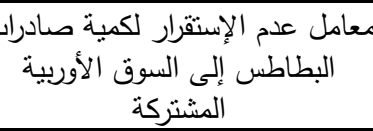 & الصادرات الكلية من الإنبطقار لقيمة & الصادرات الكلية من الإنطقار لكمية & السنوات \\
\hline 1.06 & 0.15 & 7.78 & 38.54 & 1999 \\
\hline 0.81 & 0.84 & 54.23 & 24.72 & 2000 \\
\hline 0.24 & 0.28 & 61.37 & 19.91 & 2001 \\
\hline 0.10 & 0.14 & 54.75 & 10.12 & 2002 \\
\hline 0.23 & 0.01 & 60.52 & 6.28 & 2003 \\
\hline 0.08 & 0.39 & 47.70 & 26.17 & 2004 \\
\hline 0.19 & 0.42 & 46.84 & 20.32 & 2005 \\
\hline 0.15 & 0.27 & 59.88 & 5.04 & 2006 \\
\hline 0.05 & 0.03 & 39.96 & 4.45 & 2007 \\
\hline 0.12 & 0.15 & 10.69 & 0.32 & 2008 \\
\hline 0.27 & 0.33 & 35.18 & 48.82 & 2009 \\
\hline 0.08 & 0.25 & 44.04 & 32.73 & 2010 \\
\hline 0.06 & 0.29 & 0.72 & 36.37 & 2011 \\
\hline 0.03 & 0.28 & 41.78 & 12.43 & 2012 \\
\hline 0.07 & 0.29 & 36.41 & 12.55 & 2013 \\
\hline 0.12 & 0.29 & 29.67 & 29.64 & 2014 \\
\hline 0.23 & 0.28 & 34.70 & 0.36 & المتوسط \\
\hline
\end{tabular}

المصدر: حسيط من بيانات الجدول رقم (5) بالبحث 
سادساً: تقدير دوال الطلب على الصادرات المصرية من البطاطس خلال الفترة (1999-2014) : (Angus ,John;1980,) Market Share Model نموذج المشاركة السوقية ويقدر ذللك النموذج حتى يتم التعرف على الوضع التصديرى لمحصول البطاطس المصرى فى أسواق الدول المستوردة وتقدير إمكانية تتمية الوضع التتافسى للصـادرات من السلع الزراعية فى أهم أسواقها الخارجية، وأيضـا تقدير إمكانية تقدير الوضع التتافسى لمحصول البطاطس

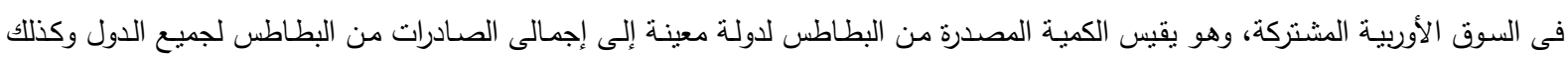
بالنسبة للسعر فهو يقيس العلاقة بين السعر الذى تستورد بـه الدولة المستوردة من مصر إلى متوسط سعر تصدير البطاطس المصرى، ويعتمد البهد

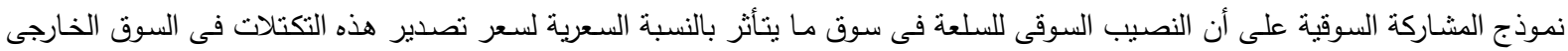
وأسعار تصدير التكتلات الأخرى المنافسـة فى هذا السوق ومن ثم فإن النصيب السوقى بستخدم كمتغير تابع والنسبة السعرية لسعر تصدير

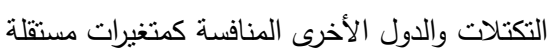

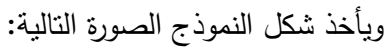

$$
\mathrm{G}=\mathrm{b}_{\mathrm{a}} \cdot \mathrm{b}_{1}+\mathrm{b}_{2} \mathrm{G}_{-1}+\mathrm{b}_{3}
$$

$\mathrm{Gi}=\mathrm{qi} / \mathrm{qj}$

النصيب السوقى للدولة فى السوق الخارجى ويتم حسابه من المعادلة:

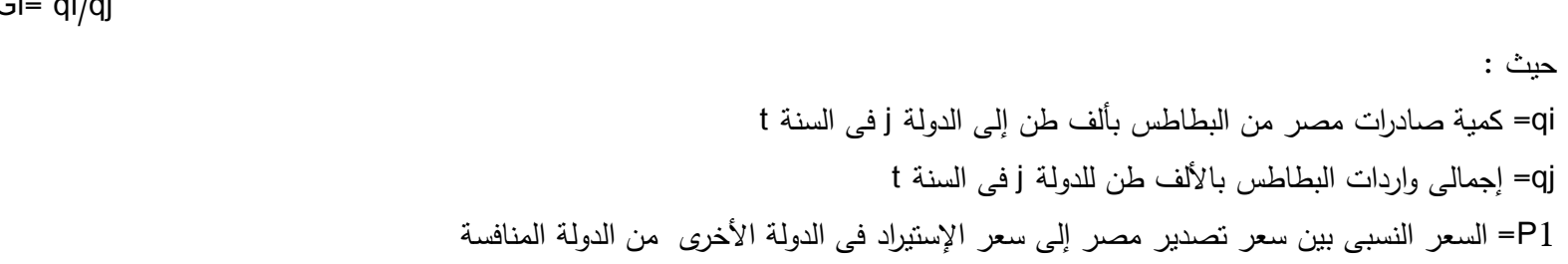

$\mathrm{P} 1=\mathrm{Pi} / \mathrm{P} 0$

t سعر التصدير المصرى للبطاطس بالدولار إلى الدولة ز فى السنة =Pi

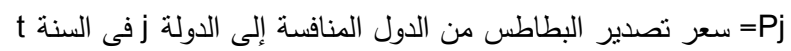

نتائج تقدير نموذج المشاركة السوقية للبطاطس:

أوضحت النتائج الواردة بجدول (7) أن قيمة معامل الإنحدار فى النموذج المقدر لكل من دولة اليونان وإيطاليا والمانيا بلغ -1.098،-0.0845، -018 وهذا يؤكد وجـود علاقـة عكسية بين السـعر النسبى للإستيراد والنصـيب السـوقى مـن البطسطس وهذا يتفق مـع النظريـة

وبلغت المرونـة السعرية لنفس الدول أيضـا -0.27 ، -0.13، -0.23 (طلب غير مرن) أى أن كلمـا زاد السعر النسبى للتصدير حدث انخفاض أقل من فى النصيب السوقى من صادرات البطاطس وهذا يعنى وجود إمكانية لزيادة سعر التصدير لكل من اليونان وإيطاليا والمانيا وبالتالى زيادة العائد التصديرى للبطاطس من فئس

فيى حين أوضحت النتائج الواردة بنفس الجدول أن قيمة معامل الإنحدار فى النموذج المقدر لكل من دولة المملكة المتحدة وهولندا بلغ

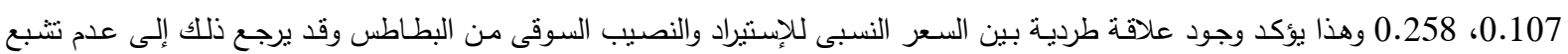
الأسواق من محصول البطاطس وزيادة الطلب الداخلى عليها 
جدول (7) نتائج تقدير نموذج المشاركة السوقية لصادرات مصر من البطاطس لأهم دول دول الإتحاد الأوربى خلا الفترة (1999-2014)

\begin{tabular}{|c|c|c|c|c|c|c|}
\hline المرونة السعرية & $F$ & R2l & للعام السابق السوقى & سعر الإستيراد & ثابت المعادلة & الدول المستوردة \\
\hline $0.27-$ & 0.656 & 0.0916 & $\begin{array}{c}0.161 \\
(0.493)\end{array}$ & $\begin{array}{c}1.098^{-} \\
\left(0.935^{-}\right)\end{array}$ & $\begin{array}{c}2.971 \\
*(2.418)\end{array}$ & اليونان \\
\hline $0.13^{-}$ & 0.709 & 0.0984 & $\begin{array}{c}0.368 \\
(1.147)\end{array}$ & $\begin{array}{l}0.0845^{-} \\
\left(0.543^{-}\right)\end{array}$ & $\begin{array}{c}0.489 \\
*(2.183)\end{array}$ & إيطاليا \\
\hline 0.12 & 1.835 & 0.2202 & $\begin{array}{c}0.498 \\
(0.276)\end{array}$ & $\begin{array}{c}0.107 \\
(0.622)\end{array}$ & $\begin{array}{l}0.401 \\
(1.23)\end{array}$ & المملكة المتحدة \\
\hline 0.13 & $* * 6.936$ & 0.5163 & $\begin{array}{c}0.836 \\
* *(3.33)\end{array}$ & $\begin{array}{c}0.258 \\
(0.596)\end{array}$ & $\begin{array}{c}0.132 \\
(0.376)\end{array}$ & هولندا \\
\hline $0.023-$ & 1.685 & 0.2059 & $\begin{array}{l}0.525 \\
(1.81) \\
\end{array}$ & $\begin{array}{l}0.018^{-} \\
\left(095 .^{-}\right)\end{array}$ & $\begin{array}{l}0.342 \\
(1.64) \\
\end{array}$ & المانيا \\
\hline
\end{tabular}

التوصيات: بناء على النتائج المتحصل عليها بوصى البحث بما يلى:

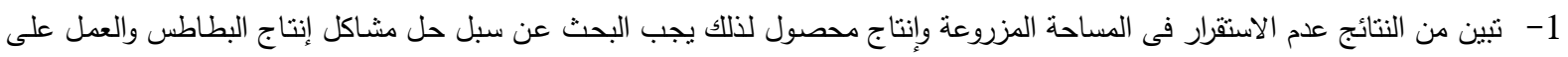
زيادة الإنتاج

2- تبين من النتائج الإرتفاع المستمر فى تكاليف إنتاج محصول البطاطس لذلك على الدولة تقديم الدعم للمنتجين ومحاولة توفير مستلزمات الإنتاج وخاصة التقاوى المستوردة المضمونة الخالية من الأمراض وخاصة مرض العفن البنى الذى يعتبر السبب الرئيسى فى رفض الإتحاد الأوربى لصادرات مصر من البطاطس وخس

3- تبين من النتائج عدم الاستقرار فى الكميات المصدرة من البطاطس وقد يرجع يرتبط ذلك بسياسات التصدير والاستيراد لمحصول البطاطس

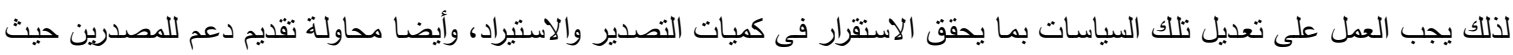
أن تكاليف تجهيز طن البطاطس للتصدير قد تصل إلى 1500 جنيه. 4- تين من النتائج عدم الاستقرار فى كمية وقيمة صادرات البطاطس المصرية إلى دول الإتحاد الأوربى وقد يرجع ذلك إلى التغيرات المستمرة فى سعر الصرف والتغيرات فى أسعار التصدير والاستيراد والثروط المجحفة فى قبول الصنادرات وتغيير معايير الجودة

المراجع 1- أحمد الموافى البهلول الموافى، دراسـة تحليلية لدور الأراضى الجديدة فى تتمية الصـادرات الزراعية المصرية، رسالة دكتوراه، كلية الزراعة بمشتهر ، جامعة بنها، 2004. 2- الجهاز المركزي للتعبئة العامة والإحصاء، نشرات التجارة الخارجية، أعداد مختلفة. 3- جلا الملاح (دكتور) "توقعات مساهمة الصادرات الزراعية في النمو الاقتصادي في مصر " المؤتمر الثاني عشر للاقتصاديين الزراعيين الميزة التتافسية للزراعة المصرية، الجمعية المصرية للإقتصاد الزراعي ، 29 - 30 سبتمبر 2004

4- داليا عبد الحميد هلال يسن، دراسة القدرات التتافسية لبعض المحاصيل البستانية المصرية، رسالة دكتوراه، كلية الزراعة، جامعة عين شمس، 2008

5- سهى مصطفى عبد العزيز الديب ، امكانيات تتمية الصـادرات المصرية لبعض الحاصلات البستانية فى الاراضى الجديدة، رسالة دكتوراه، كلية الزراعة ، جامعة عين شمس، 2009

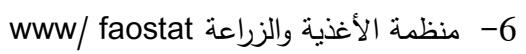

7ww/agr-egypt.gov.eg وزارة الزراعة واستصلاح الأراضي ، قطاع الثئون الإقتصادية، 2015

8- Angus Deaton and John Muellbauer, «An Almost Demand System,» American Economic Review, vol. 70, ( 7 ) no. 3 (June 1980). 


\title{
Study the economic stability for Egyptian exports of potatoes to the European Union countries
}

\author{
Amina Amin kotop Mustafa
}

Agric. Econ. Dept., Fac. Agric., Zagazig Univ., Egypt

\begin{abstract}
:
This research aims to estimate the overall time trend for each of the area, production and cost of production of potatoes in Egypt during the period 1999-2014, to estimate the relative importance of the amount of Egypt's exports of potatoes to the European Union countries in relation to the total potatoes exports, to estimate the relative importance of the value of Egypt's exports of potatoes to the European Union countries, to study the geographic distribution of the quantity and value of Egypt's exports of potatoes to the most European Union countries, to study economic stability for total potato exports and to the European Union countries, to estimate the demand function estimation on Egyptian potatoes exports using a form of market participation.

It was to rely on secondary data published and unpublished, and issued from each of the Central Agency for Public Mobilization and Statistics and the Ministry of Agriculture, Food and Agriculture of the United Nations Organization (FAO), and Foreign Trade statistics, The top five countries for imported potatoes are Greece, Italy, Germany, England and the Netherlands. To achieve the objectives of the research it was used statistical analysis, economic and standard methods by estimating the overall time trend models, for each of the cultivated area, production and cost of production, quantity and value and export price, and factor of instability, and calculating the concentration coefficient (Ginny coefficient), was used as a form of market participation for estimating function demand for potatoes exports.

The most important results: the average potatoes crop on the level of the Republic about 289.066 thousand acres, and the average production amounted to 2962.950 thousand tons, and the average amount of potatoes exports during the study period reached 361.3289 thousand tons, and the average potatoes exports to the European union countries were about 120.448 tons with relative importance of $49.35 \%$ of the total amount of potatoes exports, the average total of value exports was about 120.448 million US dollars, while the average value of the European union countries amounted to about 60.082 million dollars with relative importance of $49.88 \%$. It turned out the instability of the quantity and value of the total potatoes exports and the market of the European common, and it turned out that the regression coefficient value is estimated for each of Greece, Italy and Germany form $-1.098,-0.0845,-.018$, the value of regression coefficient for each of the United Kingdom and the Netherlands, $0.107,0.258$
\end{abstract}

